\title{
Deep and Bottom Waters in the Eastern Scotia Sea: Rapid Changes in Properties and Circulation
}

\author{
Michael P. Meredith* and Alberto C. Naveira Garabato \\ School of Environmental Sciences, University of East Anglia, Norwich, United Kingdom \\ DAVID P. STEVENS \\ School of Mathematics, University of East Anglia, Norwich, United Kingdom \\ Karen J. Heywood and Richard J. Sanders + \\ School of Environmental Sciences, University of East Anglia, Norwich, United Kingdom
}

(Manuscript received 14 April 2000, in final form 9 October 2000)

\begin{abstract}
Two meridional hydrographic transects (in 1995 and 1999) across the eastern Scotia Sea are used to investigate variability in the deep and bottom waters between the South Scotia Ridge and South Georgia. There is a significant warming of the warm deep water (WDW) south of the southern boundary of the Antarctic Circumpolar Current (ACC); waters are approximately $0.1^{\circ}-0.2^{\circ} \mathrm{C}$ warmer in 1999 than 1995 . This is due mainly to raised WDW potential temperatures in the Weddell Sea being fed through to the Scotia Sea as the WDW flows northeastward in the Weddell Gyre. There is a warming of the Weddell Sea Deep Water (WSDW) of approximately $0.05^{\circ} \mathrm{C}$ across the whole extent of the section, and an accompanying change in salinity that maintains the potential temperature-salinity relationship. This is caused by variability in the properties of the water overflowing the South Scotia Ridge, rather than enhanced outflow of the bottom layer of the Scotia Sea or movements of the ACC fronts, and may be related to changes in the intensity of the Weddell Gyre circulation. Consideration of other works suggests that the colder WSDW of 1995 is likely to be the anomalous case, rather than the warmer WSDW of 1999. The 1999 section reveals an inflow of Lower WSDW from east of the South Sandwich Arc via the Georgia Passage; this is constrained to the south of the southern boundary, and is not apparent in the 1995 measurements. Meanders in the southern boundary at Georgia Passage are likely to play a role in controlling the inflow of Lower WSDW, although changes in the peak density of the WSDW flowing across the South Scotia Ridge may be important also, with a denser inflow from the south acting to preclude an inflow of similar density from the northeast.
\end{abstract}

\section{Introduction}

The Scotia Sea (Fig. 1) lies immediately east of Drake Passage and is bounded meridionally by the North and South Scotia Ridges. The eastern limit of the Scotia Sea is the South Sandwich Arc, at approximately $25^{\circ}-30^{\circ} \mathrm{W}$. The topography of the area is extremely convoluted and plays an important role in determining the pathways of the deep and bottom waters entering the region from

\footnotetext{
*Current affiliation: Physical Sciences Division, British Antarctic Survey, Cambridge, United Kingdom.

+ Current affiliation: Southampton Oceanography Centre, Southampton, United Kingdom.
}

Corresponding author address: Dr. Michael P. Meredith, British Antarctic Survey, High Cross Madingley Rd., Cambridge CB3 OET, United Kingdom.

E-mail: mmm@bas.ac.uk the Weddell Sea and Drake Passage (e.g., Arhan et al. 1999). The water mass structure and circulation are also strongly influenced by the presence of the Antarctic Circumpolar Current (ACC). This consists of bottomreaching fronts characterized by high velocities, namely (north to south) the Subantarctic Front (SAF), the Polar Front (PF), and the Southern ACC Front (SACCF), with the southern boundary constituting the poleward extreme of the ACC (Orsi et al. 1995) (Fig. 1). South of the southern boundary lie the waters of the WeddellScotia confluence (WSC), characterized by reduced vertical gradients of water mass properties due to the injection of dense shelf waters near the tip of the Antarctic Peninsula (e.g., Whitworth et al. 1994). Poleward of this lies the cyclonic Weddell Gyre.

The densest water that enters the Scotia Sea is Weddell Sea Deep Water [WSDW; $28.26<\gamma^{n}<28.40$ (Naveira Garabato et al. 2001, manuscript submitted to Deep-Sea Res., hereafter NGHS) where $\gamma^{n}$ is the neutral 


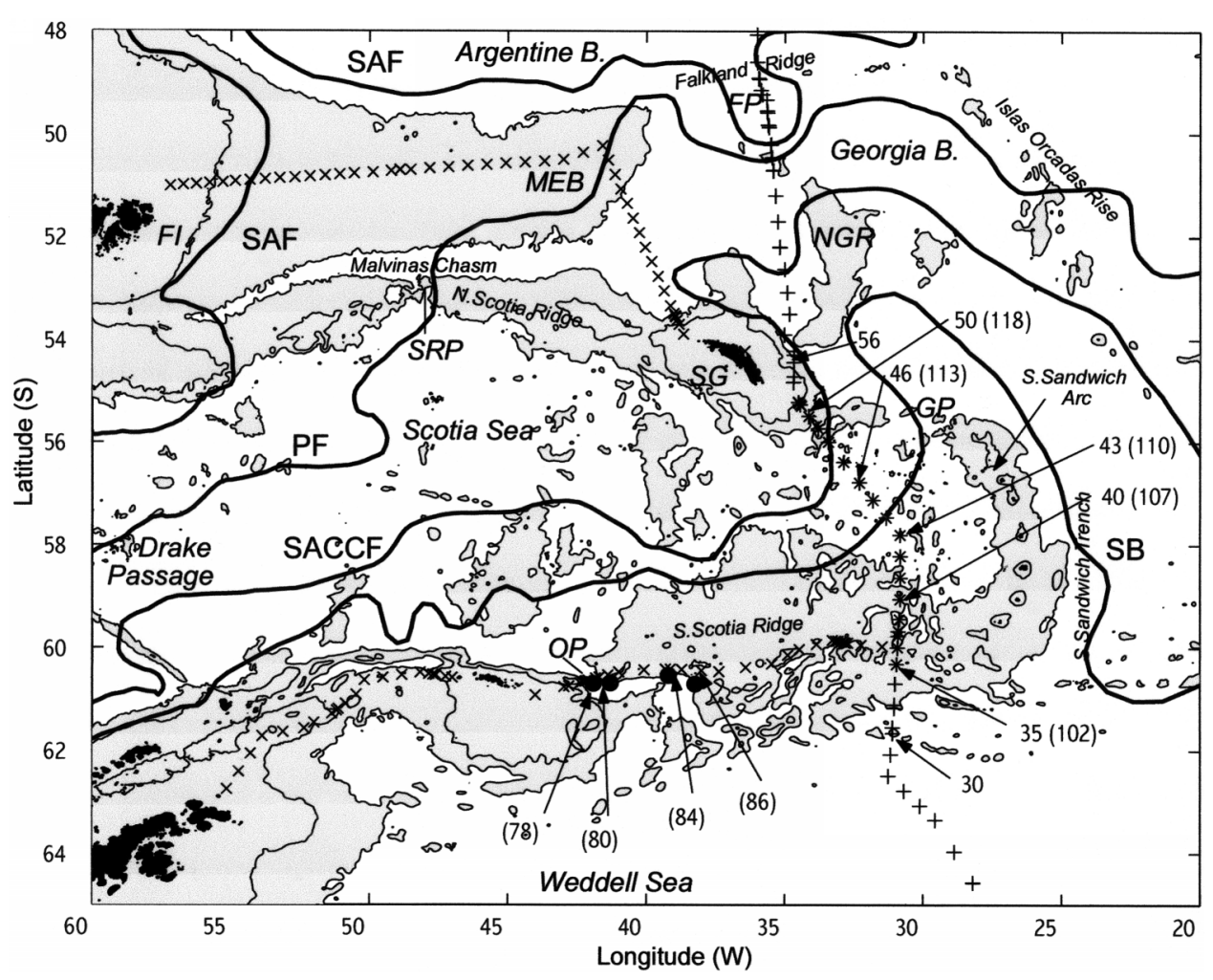

FIG. 1. Bathymetry of the Scotia Sea and surrounding environs. The 1000-m and 3000-m isobaths are marked; regions shallower than $3000 \mathrm{~m}$ are shaded. Stations in the region undertaken as part of WOCE section A23 (1995) are indicated by plusses; stations undertaken as part of the ALBATROSS cruise (1999) are indicated by crosses. Asterisks denote A23 stations repeated during ALBATROSS. Selected stations from the WOCE A23 section are numbered; selected stations from the ALBATROSS cruise are numbered parenthetically. Dots on the South Scotia Ridge mark selected stations from the WOCE S4 section (1990); these are stations 124, 125, 126, and 127, west-to-east respectively. Various topographic features are labeled by their initials, FP: Falkland Passage; MEB: Maurice Ewing Bank; FI: Falkland Islands; NGR: Northeast Georgia Rise; SRP: Shag Rocks Passage; SG: South Georgia; GP: Georgia Passage; OP: Orkney Passage. Frontal patterns of the ACC in the region are shown, SAF: Subantarctic Front; PF: Polar Front; SACCF: Southern ACC Front; SB: southern boundary of the ACC. Patterns taken from Orsi et al. (1995) and adapted following Brandon et al. (2001, manuscript submitted to Geophys. Res. Lett.), Thorpe et al. (1999), and NGSH. Water masses found in the region are listed in Table 1.

density parameter of Jackett and McDougall (1997)]. This, and the denser Weddell Sea Bottom Water (WSBW; $\gamma^{n}>28.40$ ), form near the edge of the Antarctic continent through mixing of dense shelf waters with warm deep water. WDW is identified by a potential temperature maximum at approximately $500 \mathrm{~m}$ in the Weddell Gyre and is derived from Circumpolar Deep Water (CDW) that is entrained southward into the east-

TABLE 1. Acronyms for water masses.

\begin{tabular}{ll}
\hline \hline \multicolumn{1}{c}{ Acronym } & \multicolumn{1}{c}{ Water mass } \\
\hline WSDW & Weddell Sea Deep Water \\
WSBW & Weddell Sea Bottom Water \\
AABW & Antarctic Bottom Water \\
WDW & Warm deep water \\
CDW & Circumpolar Deep Water \\
LCDW & Lower Circumpolar Deep Water \\
UCDW & Upper Circumpolar Deep Water \\
SPDW & South Pacific Deep Water \\
\hline
\end{tabular}

ern limb of the gyre (Orsi et al. 1993). Within the Weddell Sea, the key formation sites for WSDW and WSBW are the southern and western shelves (Gill 1973; Carmack and Foster 1975; Foster and Carmack 1976), although the area also receives a contribution of deep water from east of the Weddell Sea (Meredith et al. 2000). Although WSBW is bathymetrically constrained to circulate within the Weddell Gyre, WSDW can escape northward and eastward to replenish the bottom layer of the World Ocean.

Most early theories argued that the main northward pathway for WSDW from the Weddell Sea was the South Sandwich Trench to the east of the Scotia Sea (Fig. 1). It was subsequently realized that the Scotia Sea itself is an important conduit for the most recently formed WSDW (e.g., Locarnini et al. 1993), with water entering through gaps in the South Scotia Ridge, the deepest of which is the approximately $3500 \mathrm{~m}$ deep Orkney Passage near $40^{\circ} \mathrm{W}$ (e.g., Gordon 1966). After 
entering the Scotia Sea, one branch of the WSDW flows westward and is found at the southern end of Drake Passage (Sievers and Nowlin 1984). WSDW also spreads northeastward and exits the Scotia Sea through the approximately $3200 \mathrm{~m}$ deep Georgia Passage (Fig. 1). Arhan et al. (1999) placed a division on WSDW at $\sigma_{4}=46.09$ (equivalent to $\gamma^{n}=28.31$ ), with Lower WSDW being topographically constrained to enter the Georgia Basin via the South Sandwich Trench, whereas Upper WSDW could flow through the Scotia Sea and reach the Georgia Basin via the Georgia Passage. There, WSDW can flow northward into the Argentine Basin through the Falkland Passage (Fig. 1) or can recirculate southeastward out of the Georgia Basin.

In recent years at other locations, the water masses that flow through the Scotia Sea have shown significant temporal variability in properties. Coles et al. (1996) reported a warming of Antarctic Bottom Water (AABW) in the Argentine Basin in the late 1980s and argued that this was the result of a reduction in the contribution of WSDW to AABW with a consequent removal of the densest, coldest component. This was supported by Hogg and Zenk (1997), using a time series of hydrographic data from the Vema Channel (the main northern exit for WSDW in the Argentine Basin). The warming trend of WSDW in the Argentine Basin continued during the first half of the 1990s (Arhan et al. 1999). Rubython et al. (2001) observed significant interannual variability in WSDW temperature in the southern Drake Passage, with one particularly strong cold event between June 1994 and May 1995.

WDW has also shown temporal variability in recent years. Fahrbach et al. (2001, manuscript submitted to J. Geophys. Res., hereafter FMRSW) observed that the WDW in the Weddell Sea had undergone a significant and persistent warming during the 1990s. They attributed this to a previous anomalous inflow of CDW (its source water mass) into the eastern Weddell Gyre, with a consequent change in WDW properties as the anomaly propagated around the gyre.

The water masses passing through the Scotia Sea participate in the global thermohaline circulation, thus changes in their temperature, pathways, and fluxes are important in the understanding of the oceans' role in climate variability. In this paper, we use two hydrographic sections occupied 4 years apart in the eastern Scotia Sea to examine temporal variability in water mass properties. In addition, we find evidence of variability in the pathways of WSDW during its flow from the Weddell Sea.

\section{Data and methods}

Data were collected on two research cruises on RRS James Clark Ross (Fig. 1). The first was the World Ocean Circulation Experiment (WOCE) section A23 (Heywood and King 1996), conducted in 1995 as a long transect from Antarctica to Brazil. The second was the
Antarctic Large-Scale Box Analysis of the Role of the Scotia Sea (ALBATROSS) project (Heywood and Stevens 2000), which completed a box of stations around the Scotia Sea in 1999, including a repeat of the Scotia Sea stations performed as part of WOCE A23. In both cases, the repeated stations were occupied between 8 and 12 April.

On WOCE section A23, profiles of temperature, salinity, pressure, and oxygen were obtained using a Neil Brown MKIIIb conductivity-temperature-depth (CTD) profiler, and discrete water samples were taken with a 24-bottle rosette multisampler. The precision of the data is $0.001{ }^{\circ} \mathrm{C}$ for potential temperature, and 0.001 for salinity. On the ALBATROSS cruise, a Neil Brown MKIIIc CTD and 24-bottle multisampler were used, with the same precisions obtained. Batches P120 and P125 of standard seawater prepared by Ocean Scientific International Ltd. were used for salinity analysis on WOCE A23; batches P133 and P134 were used on ALBATROSS. Including uncertainties likely to be associated with "aging" of the standards (Bacon et al. 2000), we deduce salinity accuracies better than 0.002 for both cruises. Oxygen concentrations were measured on both cruises using a Winkler titration system with spectrophotometric endpoint detection similar to that described by Williams and Jenkinson (1982). Concentrations were calculated according to Dickson (1994) and used to calibrate the CTD oxygen values. Silicate concentrations were measured on both cruises using the standard colorimetric methods (Kirkwood 1995) on a Skalar San Plus autoanalyser. The precisions of the silicate (oxygen) data on WOCE A23 and ALBATROSS are estimated to be $1.3 \%$ and $1.5 \%(0.26 \%$ and $0.14 \%)$, respectively. Accuracy of the oxygen data was ensured on both cruises through the use of a commercially available standard provided by Sagami Chemical Company. Analysis of silicate levels in waters with identical potential temperature, salinity, and oxygen suggests that inconsistencies between silicate concentrations on the two cruises are less than $1 \%$. Silicate data from ALBATROSS stations 105 and 106 have been discarded due to technical problems causing reduced data quality. Discrete bottle data are not available for the upper part of WOCE A23 station 45 due to a failure of the CTD cable.

\section{Observations}

\section{a. Water mass structure of the eastern Scotia Sea}

Vertical fields of potential temperature, salinity, dissolved oxygen, silicate, and neutral density are shown in Figs. 2, 3, 4, 5, and 6, respectively. The SACCF is at the northern end of the sections, close to South Georgia (near station 50 in 1995 and 118 in 1999). This loops anticyclonically around the island before retroflecting and continuing eastward around the Northeast Georgia Rise (Fig. 1). The southernmost location of the 
southern boundary is near $58.5^{\circ} \mathrm{S}$ in the $\mathrm{A} 23$ sections and near $59^{\circ} \mathrm{S}$ in the ALBATROSS sections. This veers northeastward after crossing the sections and lies close to the Georgia Passage as it exits the Scotia Sea (Fig. 1). Particularly striking on each section is the presence of a narrow, cyclonic recirculation of the southern boundary near $57.5^{\circ} \mathrm{S}$. Its apparent persistence argues against it being a transient eddy and suggests that it is possibly a permanent feature, perhaps related to the local topography. However, from examination of bathymetric charts, the predicted bathymetry of Smith and Sandwell (1997), and our own soundings we have found no distinct topographic features that we suspect to be responsible. It is remarkably similar to a feature commonly observed on sections across the eastern Drake Passage (WOCE line SR1b; Burdwood Bank to Elephant Island). This has been detected on almost every occasion that the section has been occupied (e.g., Garcia et al. 1997; Meredith et al. 1999) and (as with the feature observed here) is normally present in just one hydrographic station. The dynamical nature of these features remains unclear, but it appears that they may be more widespread in the region than was previously thought.

The bottom layer at the southern end of the repeat section is Lower WSDW $\left(\gamma^{n}>28.31\right)$. This thins progressively to the north, disappearing by approximately $57^{\circ} \mathrm{S}$. Above this is an approximately 1000 -m thick layer of Upper WSDW (28.26 $<\gamma^{n}<28.31$; Fig. 6). Values of silicate for the WSDW are high (close to 125-130 $\mu \mathrm{mol} \mathrm{kg}{ }^{-1}$; Fig. 5) due to interaction with sediments in the Weddell Sea (Weiss et al. 1979).

The CDW of the ACC can be separated at $\gamma^{n}=28.00$ into Lower CDW (LCDW, marked by a salinity maximum; Fig. 3) and Upper CDW (UCDW, marked by a potential temperature maximum and an oxygen minimum south of the PF; Figs. 2, 4). Both CDW types are observed along the section north of the southern boundary. UCDW becomes entrained into the surface layer of the Weddell Gyre at the southern boundary. LCDW on the section lies generally between the southern boundary and the SACCF, with potential temperature and salinity increasing northward (Figs. 2, 3). Adjacent to the shelf slope of South Georgia, there is evidence of a remnant of South Pacific Deep Water (SPDW) (NGHS), seemingly influenced by the topography and the presence of the SACCF.

The water mass above the Upper WSDW poleward of the southern boundary is WDW, characterized by maxima in potential temperature and salinity (Figs. 2, 3 ) and a minimum in dissolved oxygen (Fig. 4). On the sections shown, the region south of the southern boundary is the WSC (approximately $59^{\circ}-60.5^{\circ} \mathrm{S}$ ). For the WOCE A23 section, the core of the WSC is found at stations 35 and 36 (Meredith et al. 2000); on the ALBATROSS section, the southernmost station (102) shows the strongest WSC influence.

The WDW nearest the southern boundary has higher potential temperature and salinity values than farther
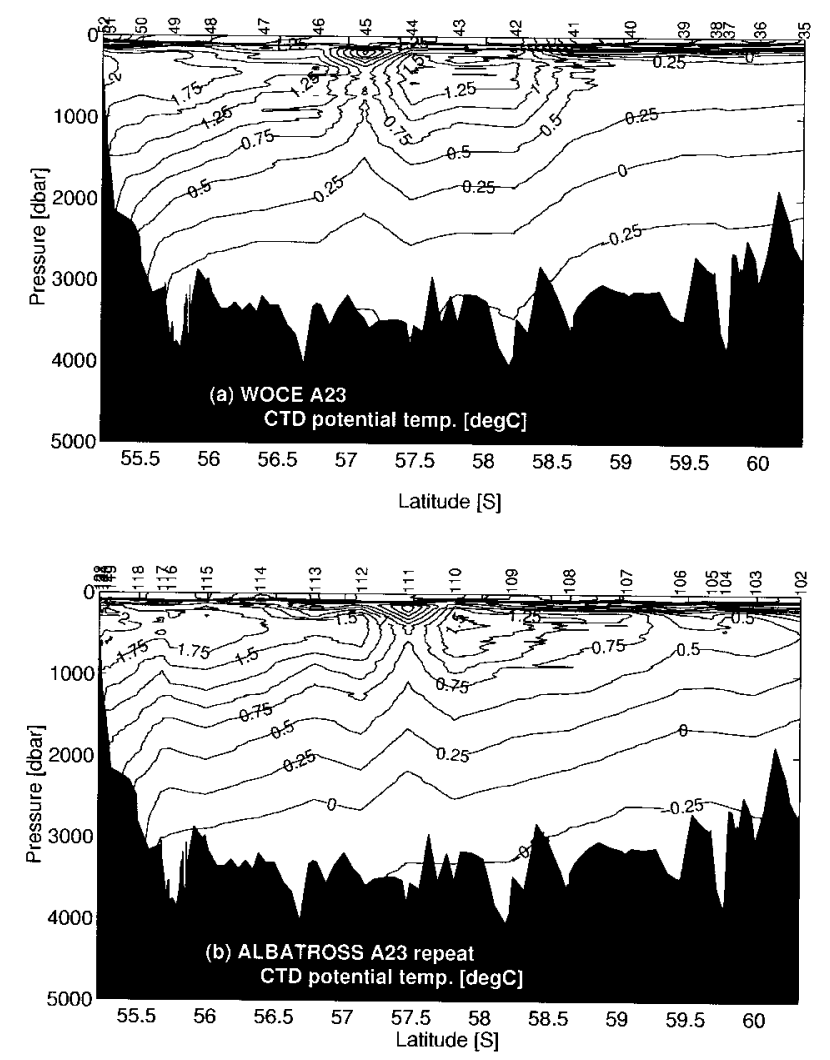

FIG. 2. Potential temperature in the eastern Scotia Sea from CTD measurements. Upper panel is from the WOCE section A23 in 1995; lower panel is from the ALBATROSS cruise in 1999. Station locations are marked by cruise station numbers above the uppermost horizontal axis.

south due to mixing with CDW. WDW lighter then $\gamma^{n}$ $=28.20$ is constrained to lie south of the southern boundary, with the exception of the recirculation near $57.5^{\circ} \mathrm{S}$ that features WDW north of the southernmost position of the southern boundary on the sections. The denser WDW observed farther north has most likely originated from SPDW transformed by mixing with WSDW or WDW south of the Southern Boundary (NGHS).

\section{b. Changes between 1995 and 1999}

One of the most obvious differences between the sections concerns the WDW layer. In 1995, the entire WDW layer in the Scotia Sea south of the southern boundary was cooler than $0.45^{\circ} \mathrm{C}$, with most potential temperatures between $0.35^{\circ}$ and $0.4^{\circ} \mathrm{C}$ (Fig. 7). Conversely, in 1999 the WDW layer for the same oceanic regime was entirely warmer than $0.45^{\circ} \mathrm{C}$, with most potential temperatures between $0.5^{\circ}$ and $0.6^{\circ} \mathrm{C}$. (Fig. 7 compares water from the same oceanic regime in 1995 and 1999, not simply water from the same geographical locations. Thus, given that there is no overlap between any of the curves at the WDW core, the change in 

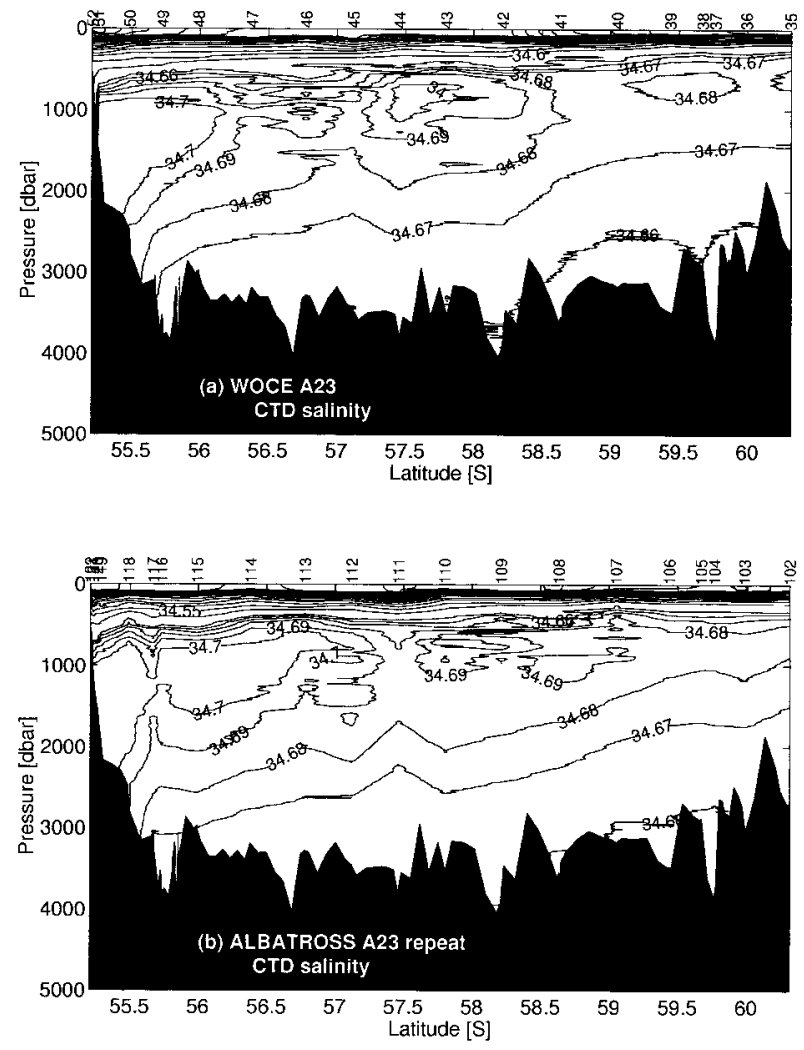

FIG. 3. As in Fig. 2 but for salinity.

temperature cannot be due to variability in the location of fronts in the region.) The potential temperature maximum of the UCDW layer north of the southern boundary remains unchanged.

The difference in potential temperature-salinity space is also profound. Adopting the nomenclature of Whitworth et al. (1994), the WOCE A23 stations lie very close to the "Weddell Sea sequence," while the ALBATROSS stations lie further into the "ACC/WSC sequence" (i.e., stronger influence of the warmer, saltier CDW from farther north; Fig. 8). The potential temperature and salinity maxima at the time of WOCE A23 are much more tightly constrained compared with the large spread in values at the ALBATROSS core extrema. WOCE A23 station 40 is the only 1995 station to show strong influence of mixing with ACC water, and only for waters lighter than $\gamma^{n}=28.15$. Note also the marginally lower density of the WDW core layer in 1999 compared with that in 1995 (Fig. 8).

Another significant difference between the sections concerns the WSDW layer, which was approximately $0.05^{\circ} \mathrm{C}$ warmer in 1999 than 1995 (Fig. 9). Stations close to the southern boundary and farther south (represented by the ALBATROSS station 107/WOCE A23 station 40 pair in Fig. 9) show raised temperatures in the WDW as well as in WSDW (the WDW warming discussed previously). Most stations farther north show significant warming only in the WSDW layers (e.g., ALBATROSS
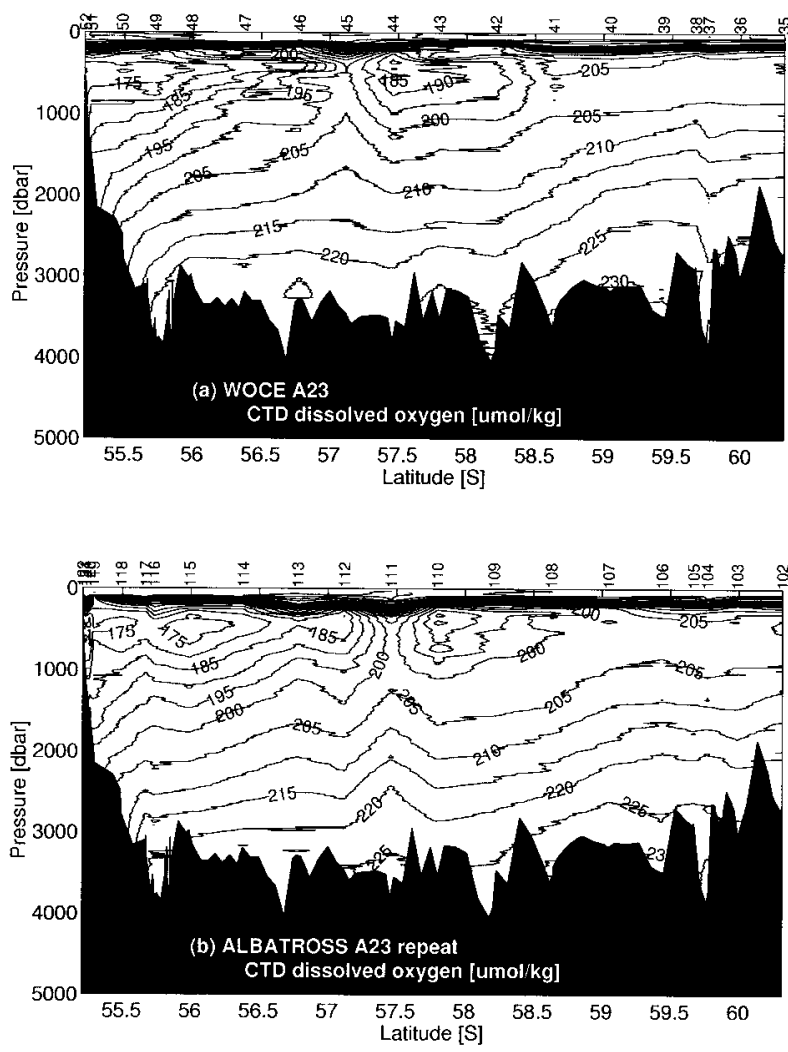

FIG. 4. As in Fig. 2 but for dissolved oxygen.

station 113 and WOCE A23 station 46 in Fig. 9), although in the vicinity of ALBATROSS station 115 there is some evidence of higher potential temperatures above this layer, probably due to a weak recirculation of more northerly waters (note the slight reversal of isoneutrals around ALBATROSS station 115 in Fig. 6; this is not present in the WOCE A23 section).

The WSDW warming is not solely apparent in comparisons of pairs of stations from the same geographical locations; it is also apparent when one considers the properties within oceanic regimes. For example, Fig. 10 shows all the stations south of the southern boundary, and it is clear that the 1999 WSDW potential temperatures within this regime are consistently offset compared with 1995. Some stations show evidence of this warming over most of the depth range of WSDW, but have seemingly invariant potential temperature at the very bottom (e.g., WOCE A23 37 and ALBATROSS 104 in Fig. 10). There are good reasons, however, to believe that the water at the very bottom of such stations has also been replaced between 1995 and 1999, albeit with water of the same potential temperature (see below).

The increase in WSDW potential temperature is accompanied by a corresponding increase in salinity (Fig. 3 shows a general deepening of the deep isohalines between 1995 and 1999). The potential temperature-salinity curves for deep and bottom waters (not shown) 

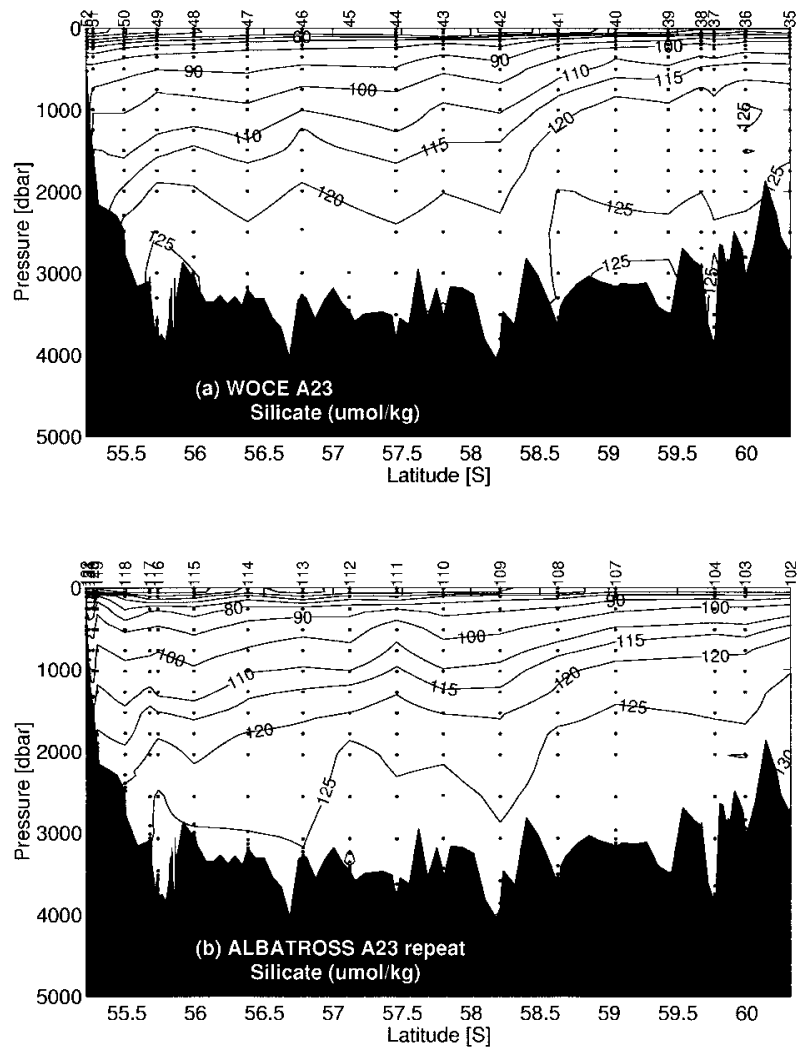

FIG. 5. As in Fig. 2 but for dissolved silicate from discrete samples. Locations of discrete water samplings are marked with dots.

remain the same from 1995 to 1999 , but with the same density contours sitting lower in the water column in 1999 compared with 1995 (Fig. 6), indicative of a smaller volume of WSDW in the eastern Scotia Sea in 1999. The dissolved oxygen contours (Fig. 4) mimic this behavior, again sitting deeper in the water column in 1999 compared with 1995.

The observed WSDW warming cannot be due to variability in the locations of the fronts in the region, since it is seen consistently in comparisons of groups of stations from the same oceanic regime (e.g., south of the Southern Boundary in Fig. 10), and is also seen across the full meridional extent of the Scotia Sea at this longitude (Fig. 9 shows example stations from both north and south of the southern boundary). Note that stations north of the southern boundary (e.g., the WOCE A23 46/ALBATROSS 113 station pair in Fig. 9) only show warming in the WSDW layer since the waters above are not subject to the WDW warming south of the Southern Boundary. A shift in the location of a front would affect the temperature of the whole water column; consequently it cannot be the cause of the observed change. Furthermore, a southward shift of the southern boundary (such as would be required to produce higher abyssal temperatures) would be accompanied by lower dissolved silicate concentrations. (Similarly, warmer WSDW due to enhanced outflow of the bottom later from the Scotia Sea and a consequent downward shift of isotherms would be accompanied by a lowering of silicate concentrations.) As shown in Fig. 5, the converse was observed. Thus, instead of variability in the positions of fronts, a change in the characteristics of the inflow to the Scotia Sea is required to explain the observed change in WSDW properties.

There is an additional change that affects solely the Lower WSDW. Figure 11 shows the potential temperature-salinity curves for stations south of the southern boundary in 1995 and 1999. There is a distinct discontinuity in the ALBATROSS curves at $\gamma^{n}=28.31$; below this they divert toward higher salinity. Such a discontinuity is absent from the WOCE A23 curves. This indicates the presence of an additional water mass in the eastern Scotia Sea in 1999, compared with 1995. Its influence is greatest in the deepest levels, reducing with decreasing depth through the Lower WSDW layer, and is not discernible above the Lower WSDW. It is thus a thin, deep, saline layer, which we will demonstrate enters the Scotia Sea having flowed around the eastern flank of the South Sandwich Arc. Stations north of the southern boundary that feature Lower WSDW (i.e., northward up to station 111) show no evidence of such a discontinuity, implying a controlling role for the southern boundary in the spreading of the new, more saline, water.

Comparison of Figs. 10 and 11 shows that, for station pairs such as ALBATROSS 104/WOCE A23 37 (where the potential temperature at the bottom did not change between 1995 and 1999), the salinity at the seabed increased slightly (by approximately 0.002). Thus, for such stations there are two changes in the WSDW between 1995 and 1999, with the waters above approximately $\gamma^{n}=28.31$ being warmed and made marginally more saline (and hence showing the same potential temperature-salinity relationship), whereas at greater depths the waters are more saline but have the same potential temperature (and hence show a deviation towards higher salinity in the potential temperature-salinity curves).

To summarize, the main observations of note in these eastern Scotia Sea sections are 1) a strong warming (approximately $0.1^{\circ}-0.2^{\circ} \mathrm{C}$ ) of the WDW layer south of the southern boundary from 1995 to 1999, 2) a significant warming (approximately $0.05^{\circ} \mathrm{C}$ ) of the WSDW both north and south of the Southern Boundary, with a corresponding change in salinity that maintained the potential temperature-salinity relationship, and 3) a salinification of the Lower WSDW at and south of the southern boundary between 1995 and 1999 with no discernible accompanying change in potential temperature. The likely causes and effects of these observations are now discussed.

\section{Discussion \\ a. WDW warming}

The WDW warming south of the southern boundary is in accord with the persistent warming of WDW in 

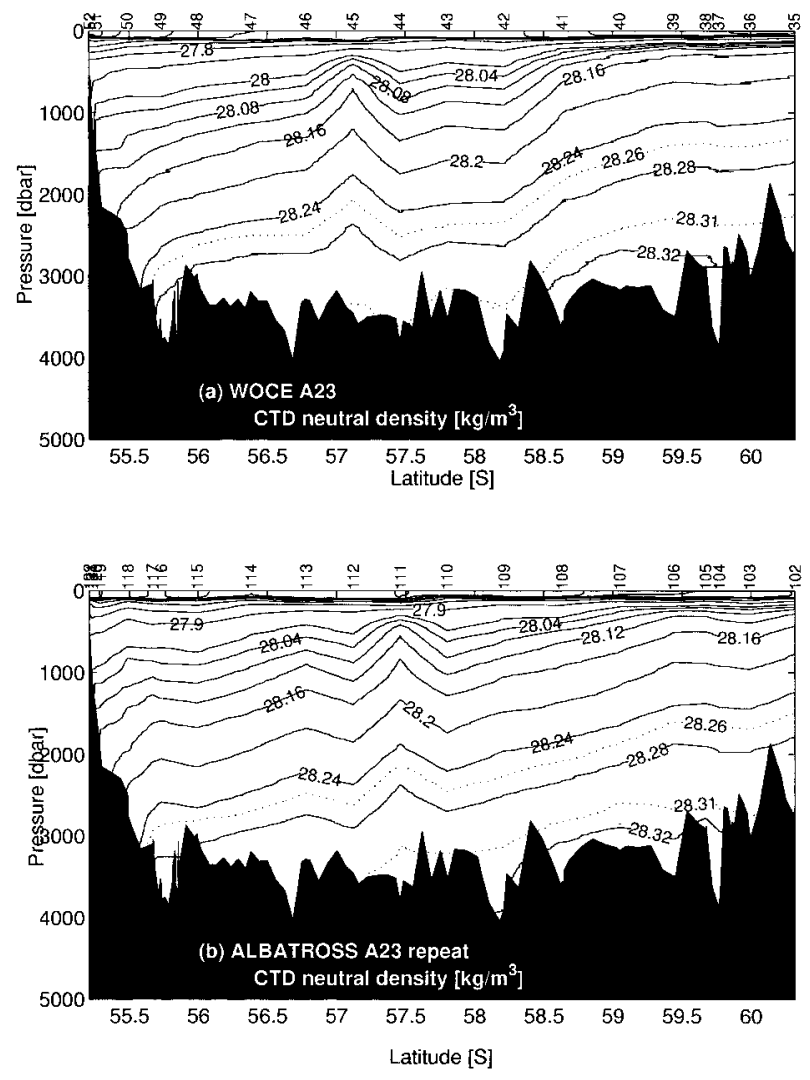

FIG. 6. As in Fig. 2 but for neutral density $\left(\gamma^{n}\right)$.

the Weddell Sea during the 1990s observed by FMRSW. Since the WDW sampled in the Scotia Sea is supplied from the Weddell Sea, such a warming could be expected in our data. This change in potential temperature of the WDW supplied to the Scotia Sea is also demonstrated in Fig. 12, which shows the potential temperature maxima for ALBATROSS stations (1999) across the gaps of the South Scotia Ridge, alongside those from WOCE section S4 (1990) from nearly identical locations (see Fig. 1 for station positions). The warming is apparent at nearly all locations, with a typical value of approximately $0.3^{\circ} \mathrm{C}$. Given the persistence of the warming in the Weddell Sea (FMRSW) and the different time intervals between cruises ( 4 and 9 years), one expects a change in WDW potential temperature somewhat smaller than $0.3^{\circ} \mathrm{C}$ to be associated with the change in WDW inflow to the Scotia Sea between 1995 and 1999. The changes we observe are generally of order $0.1^{\circ}-0.2^{\circ} \mathrm{C}$ (Fig. 7 ).

We can exclude enhanced mixing with ACC waters (in 1999, compared with 1995; Fig. 8) as being the main cause for the observed increase in WDW temperature in the Scotia Sea. NGSH showed that ALBATROSS station 86 on the South Scotia Ridge (Fig. 12) represents almost pure Weddell Gyre WDW; that is, it provides a good indication of the WDW properties in 1999 prior to their mixing with ACC waters. Its core potential tem-

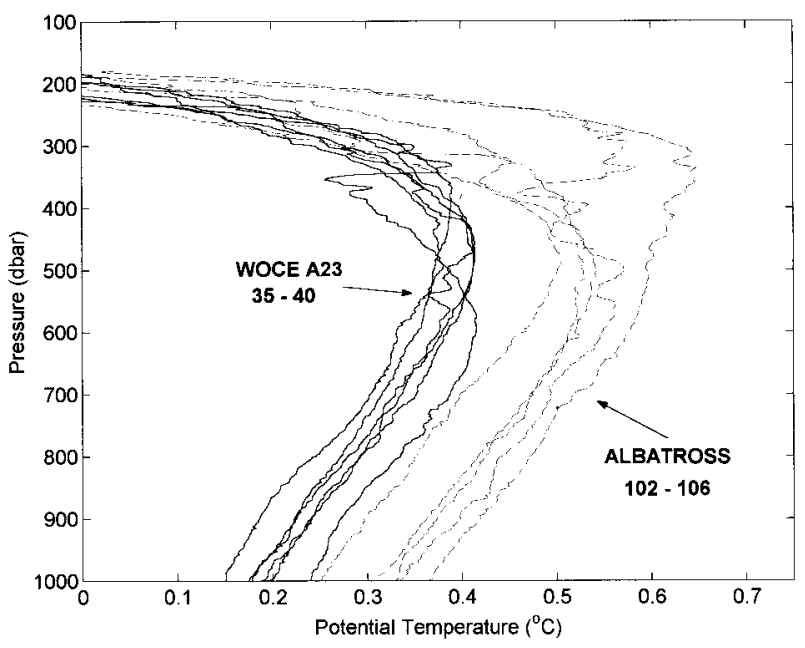

FIG. 7. Potential temperature vs pressure from CTD data for stations south of the southern boundary. Solid lines are stations 35-40 from WOCE section A23; dashed lines are stations 102-106 from the ALBATROSS cruise (see Fig. 1 for station locations). Note the significant difference in potential temperature at its maximum (the core WDW layer).

perature maximum $\left(0.58^{\circ} \mathrm{C}\right)$ is close to the core WDW potential temperature measured in the eastern Scotia Sea during the same cruise (approximately $0.5^{\circ}-0.6^{\circ} \mathrm{C}$; Fig. 7 ), but is very much higher than the core WDW potential temperatures there at the time of WOCE A23 (approximately $0.35^{\circ}-0.4^{\circ} \mathrm{C}$; Fig. 7 ). Any WDW warming due to mixing with the ACC is thus much smaller than that due to the raised potential temperatures of the WDW entering from the Weddell Sea. It is possible that variability in the amount of shelf water incorporated into the WSC could affect water mass properties downstream

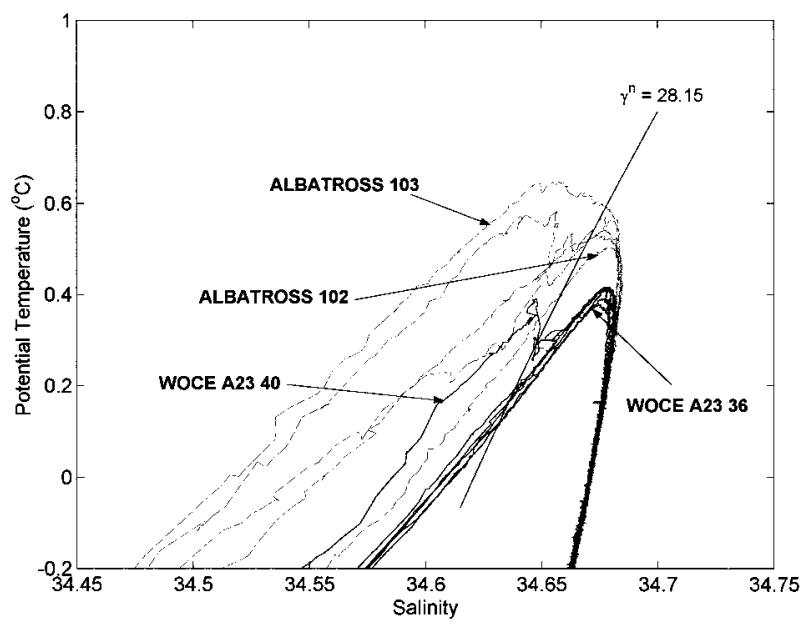

FIG. 8. As in Fig. 7 except salinity vs potential temperature. WOCE A23 station 36 represents the core of the WSC at this longitude; WOCE A23 station 40 shows some mixing with ACC water. The $\gamma^{n}$ $=28.15$ isoneutral is superposed. The strongest WSC influence in 1999 is found at ALBATROSS station 102; the adjacent station (103) shows strong influence of mixing with the ACC. 


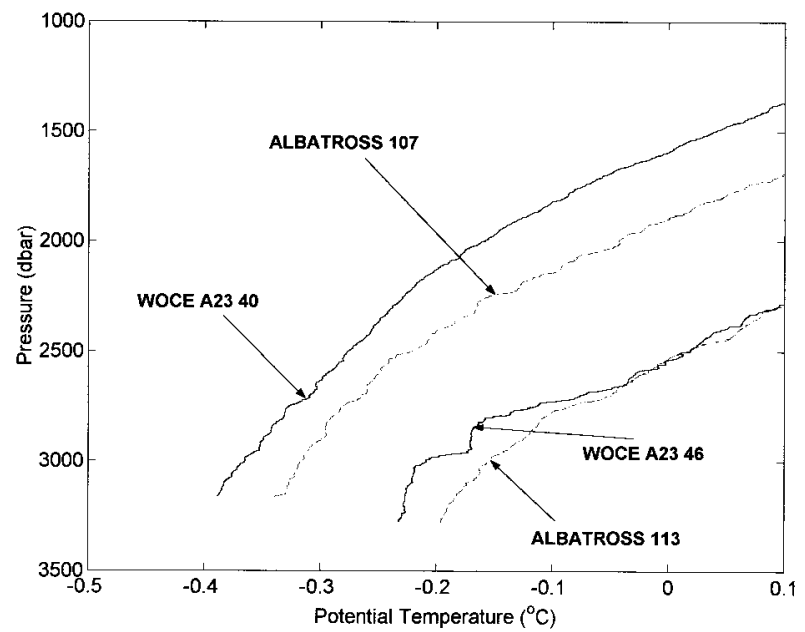

FIG. 9. Potential temperature vs pressure for WOCE A23 stations 40 and 46, and ALBATROSS stations 107 and 113. Paired stations are from the same locations. Note the warmer WSDW in 1999 (dotted) compared with 1995 (solid). North of the Southern Boundary, warming is present only in the WSDW layers, but extends higher in the water column farther south due to the WDW warming there (e.g., Fig. 7).

in the Scotia Sea. Specifically, a year that featured a smaller injection of shelf water into the WSC would result in a WDW layer that was warmer, more saline, and with lower dissolved oxygen concentrations. However, such a process cannot be a contributor to the observed WDW warming since our dissolved oxygen data reveal no evidence of a decrease in concentration. Consequently, the raised WDW temperature in the Weddell Sea being fed through to the Scotia Sea seems to be dominant cause for the WDW warming observed.

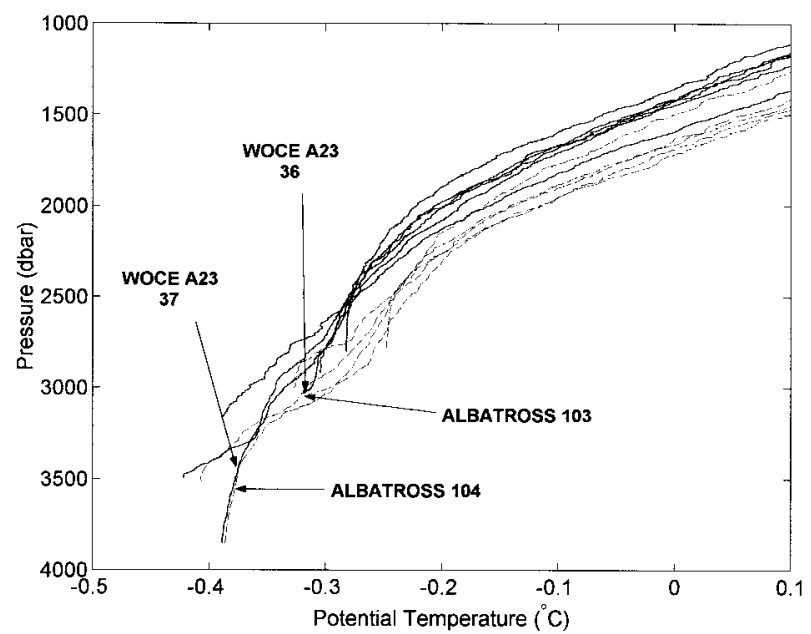

FIG. 10. Potential temperature vs pressure for stations south of the southern boundary. WOCE A23 stations (solid) are consistently offset cooler than ALBATROSS stations (dotted), except for station pairs such as WOCE A23 37/ALBATROSS 104 and WOCE A23 36/ALBATROSS 103 where the warming does not extend completely to the seabed.
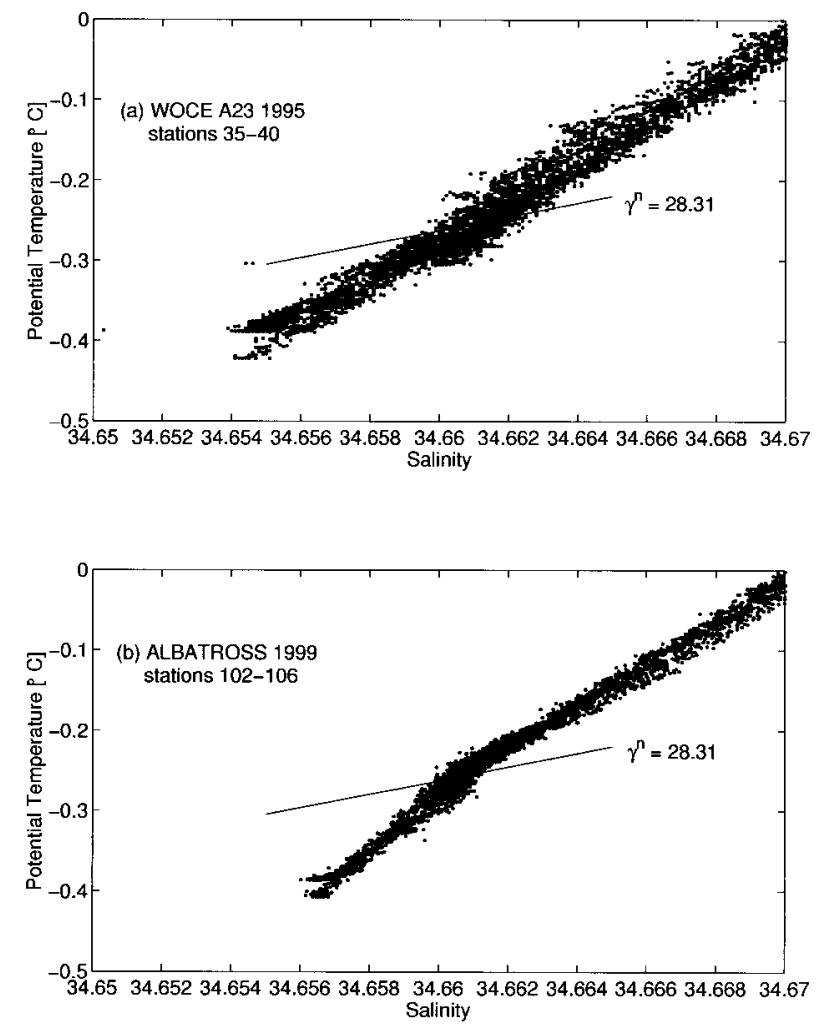

FIG. 11. Salinity vs potential temperature from CTD data for (a) WOCE A23 stations 35-40, and (b) ALBATROSS stations 102-106. Note the discontinuity in the ALBATROSS curves at approximately $\gamma^{n}=28.31$ (the division between Lower WSDW and Upper WSDW). In comparison to the WOCE A23 curves, the ALBATROSS curves divert toward higher salinity below this density.

\section{b. WSDW warming}

We have observed a warming of the WSDW across the full meridional extent of the Scotia Sea at this longitude due to changes in the WSDW overflowing the South Scotia Ridge rather than local variability. Rubython et al. (2001) presented a 4-yr time series of bottom temperature at Drake Passage and observed an anomalously cold period (June 1994-May 1995) during which the WSDW was approximately $0.1^{\circ} \mathrm{C}$ colder than before or after. They noted that the change was accompanied by a change in salinity such that the potential temperature-salinity curves remained unaltered, except for terminating at different values. This is identical to the nature of the changing WSDW properties in the eastern Scotia Sea observed here. The WOCE A23 section was performed in March-April 1995 (i.e., during the period of the anomaly at Drake Passage), thus it seems likely that the same potential temperature anomaly was sampled. A consequence is that the WOCE A23 WSDW should probably be considered anomalously cold for the eastern Scotia Sea, rather than the ALBATROSS WSDW being considered anomalously warm.

Rubython et al. (2001) argued that the anomaly at 


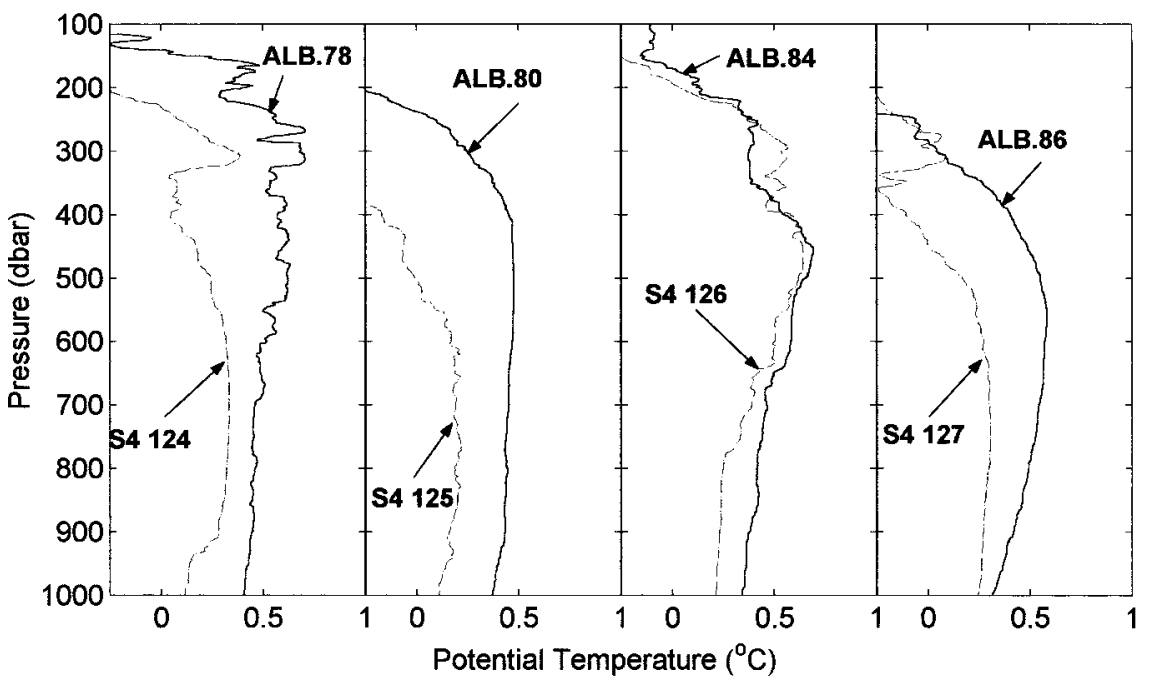

Fig. 12. Potential temperature vs pressure for ALBATROSS stations 78, 80, 84, and 86 (1999) and WOCE section S4 stations 124-127 (1990) from nearly identical locations on the South Scotia Ridge (Fig. 1). Note the general warming at the potential temperature maximum of the WDW core.

Drake Passage was the result of colder WSDW overflowing the South Scotia Ridge through Orkney Passage. We also consider this the most likely explanation (although for our case anomalies could also propagate through gaps farther east of Orkney Passage). As evidence, Fig. 13 shows the potential temperature-silicate relationship for stations in the northern Weddell Sea occupied during WOCE A23. This is just downstream of the locations where the WSDW enters the Scotia Sea prior to being sampled on the sections used here. The coldest WSDW entering the Scotia Sea through gaps in

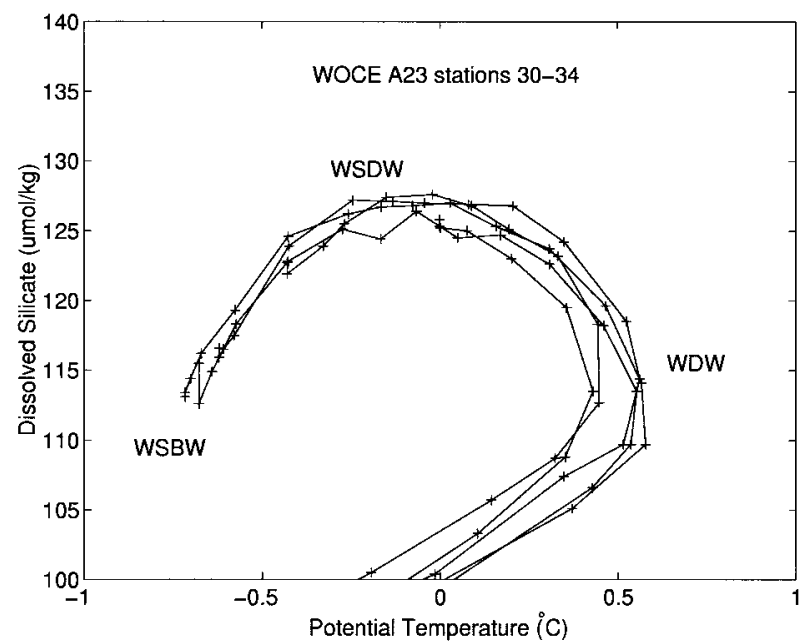

FIG. 13. Potential temperature vs dissolved silicate for WOCE A23 stations 30-34 in the northern Weddell Sea (see Fig. 1 for station locations). Note the lower silicate values toward lower potential temperatures between WSDW and WSBW; an inflow of anomalously cold water to the Scotia Sea would thus feature lower dissolved silicate values. the South Scotia Ridge has potential temperatures colder than $-0.5^{\circ} \mathrm{C}(\mathrm{NGSH})$; below this level, there is a decrease in dissolved silicate with decreasing potential temperature. Consequently, an inflow of anomalously cold WSDW to the Scotia Sea (such as was inferred to have occurred prior to the WOCE A23 section) would be accompanied by lower dissolved silicate concentrations; this is in accord with the pattern of the WOCE A23 and ALBATROSS data. While the silicate levels observed in the eastern Scotia Sea correspond to potential temperatures above $-0.5^{\circ} \mathrm{C}$, the ALBATROSS east Scotia Sea section crosses the coldest outflow from the Scotia Sea (e.g., NGSH). Consequently, the coldest overflow from the South Scotia Ridge must mix upward within the Scotia Sea before crossing the cruise track in the eastern Scotia Sea, thus transferring the raised silicate levels in 1999 to the waters above.

We can exclude a change in the amount of shelf water intruding from near the Antarctic Peninsula as being a dominant cause of the change in WSDW temperature. The WSDW seen in the eastern Scotia Sea enters the region through Orkney Passage (Fig. 1) and farther east (NGSH). Gordon et al. (2001, manuscript submitted to J. Geophys. Res.) and NGSH show that WSDW crossing the South Scotia Ridge in the deep passages east of the South Orkneys is not significantly affected by ventilation with shelf water from the peninsula. A similar argument was invoked by Rubython et al. (2001), who showed that the WSDW they sampled in Drake Passage did not enter the Scotia Sea in the vicinity of the Powell Basin (approximately $50^{\circ} \mathrm{W}$; immediately south of the South Scotia Ridge), but farther east in the vicinity of the Orkney Passage.

The cause of the anomalously cold WSDW overflow 
prior to sampling on WOCE A23 cannot be determined unambiguously. Rubython et al. (2001) considered oxygen isotope data from Drake Passage, and argued that there had been a change in formation properties (and possibly the dominant formation location) in the Weddell Sea. This is a possibility; however it is important to note that a change in isotopic composition need not be associated with a change in the density structure of the water column, hence the difference in isotopic composition need not be related to the temperature variability. A denser flow over the South Scotia Ridge could only occur if the whole water column in the Weddell Sea beneath the depth level of the overflow were made denser; otherwise, there would simply be a vertical readjustment with no change in overflow properties.

A second possibility relates to an argument originated by Martinson et al. (1982), and revisited by Coles et al. (1996). The latter authors argued that the intensity of circulation of the Weddell Gyre will impact on the density of water overflowing the topography of the South Scotia Ridge (their Fig. 11). During a period of anomalously weak gyral circulation, the isopycnals near the gyre boundaries will slump closer to horizontal compared with periods of strong gyral circulation. This leveling of isopycnals will act to raise denser water higher in the water column, thus supplying denser water to the depth levels of the bottom of the gaps in the South Scotia Ridge. Such a process would explain the increases in WSDW potential temperature, salinity, and dissolved silicate between 1995 and 1999, with the exception of the higher salinity of Lower WSDW (which featured no corresponding change in potential temperature).

\section{c. Lower WSDW salinification}

The only places where water as dense as Lower WSDW $\left(\gamma^{n}>28.31\right)$ can enter the Scotia Sea are 1) the South Scotia Ridge, especially Orkney Passage, and 2) the South Sandwich Arc where the Georgia Passage is the only area deep enough to be of relevance. Arhan et al. (1999) noted that the WSDW that flows along the southern flank of the South Scotia Ridge, then northward on the eastern side of the South Sandwich Arc, is more saline for a given potential temperature than the WSDW that crosses the South Scotia Ridge to enter the Scotia Sea. This is demonstrated in Fig. 14 using stations from the WOCE A23 section just south of the South Scotia Ridge. Mixing with this water would result in a shift of Scotia Sea potential temperature-salinity curves toward higher salinity. Arhan et al. (1999) noted such a change for stations in the Georgia Basin where WSDW from the Scotia Sea is undercut by Lower WSDW that has flowed around the eastern flank of the South Sandwich Arc. Consequently, the more saline Lower WSDW observed on ALBATROSS (compared with the WOCE A23 data) is indicative of an inflow of the Lower WSDW from east of the island arc. The Georgia Passage, at the northern end of the arc and just southeast

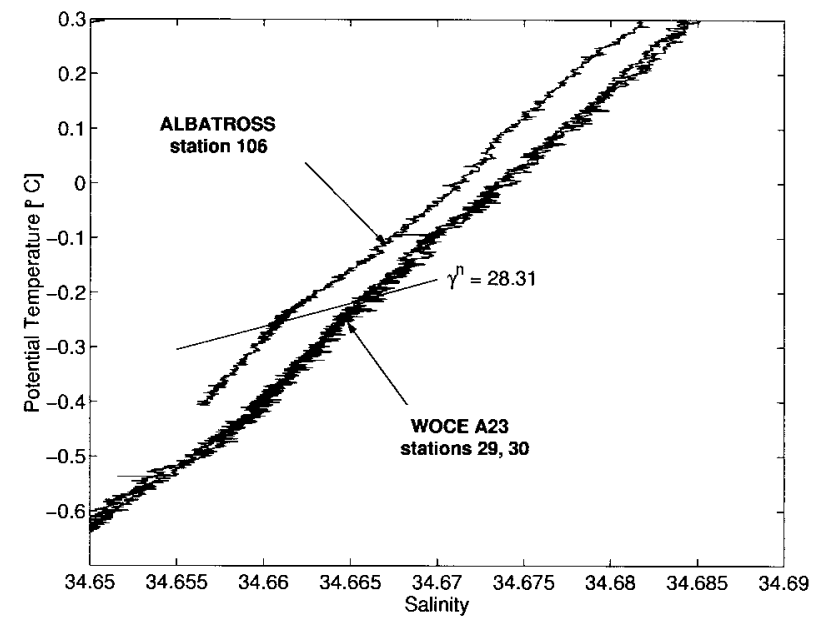

FIG. 14. Salinity vs potential temperature for WOCE A23 stations 29 and 30, northern Weddell Sea. These waters are representative of the more saline WSDW that flows east of the South Sandwich Arc, as compared with the fresher WSDW that flows through the Scotia Sea. The discontinuity in the ALBATROSS potential temperaturesalinity curves at the boundary of the Lower WSDW (here depicted in the station 106 data) indicates the inflow of saline Lower WSDW through Georgia Passage.

of South Georgia, is the only site where this inflow could feasibly occur. The observation of greatest deviation from WOCE A23 conditions at the bottom of the potential temperature-salinity curves is an indication of a thin bottom layer of Lower WSDW intruding southward through Georgia Passage and undercutting the WSDW there. Conversely, at the time of WOCE A23, all the WSDW sampled seems to have entered the Scotia Sea over the South Scotia Ridge.

The inflow of Lower WSDW from the eastern side of the South Sandwich Arc results in changes in salinity south of the Southern Boundary that extend to the seabed. However, the inflow of warmer WSDW over the South Scotia Ridge does not affect the bottom of profiles at every station (Fig. 10). The bottom waters of these stations have been replaced by more saline waters from around the South Sandwich Arc, whereas the WSDW above has been replaced by warmer WSDW that has crossed the South Scotia Ridge. Therefore the densest Lower WSDW that entered via Georgia Passage was denser than the densest WSDW that overflowed the South Scotia Ridge prior to being measured on ALBATROSS. It is possible that the overflow at the South Scotia Ridge prior to WOCE A23, being colder (and therefore denser), was sufficiently dense to preclude the invasion of Lower WSDW from around the island arc. If true, given that other evidence (e.g., Rubython et al. 2001) suggests that WOCE A23 should be regarded as anomalous rather than ALBATROSS, it seems likely that the inflow of Lower WSDW into the Scotia Sea via Georgia Passage is the more normal condition.

The mean position of the Southern Boundary lies close to the Georgia Passage (Fig. 1). As with meanders 
of the PF controlling the northward flux of SPDW at Shag Rocks Passage, it is likely that northward (southward) meanders of the southern boundary across Georgia Passage act to permit (preclude) an inflow of Lower WSDW from the east. This theory is given some credence by the presence of the discontinuity in the potential temperature-salinity curves only at stations at and south of the southern boundary. This implicates the southern boundary in controlling the entry of Lower WSDW at the Georgia Passage, with the water that does enter flowing southward on the western flank of the South Sandwich Arc and thereafter being constrained to lie south of the southern boundary.

The discontinuity in the potential temperature-salinity curves implies that appreciable quantities of only Lower WSDW enter via the Georgia Passage. This raises the question of why similar amounts of Upper WSDW do not also enter, with a consequent salinification of all WSDW south of the Southern Boundary. Arhan et al. (1999) noted a discontinuity similar to that in Figs. 11 and 14 at a slightly less dense level in the potential temperature-salinity profiles of the Georgia Basin. They argued that the dominant flow of Upper WSDW is over the South Scotia Ridge, then northward through the Scotia Sea, with flow of Upper WSDW around the South Sandwich Arc being much weaker by comparison [see also Locarnini et al. (1993)]. Consequently, when the two flows merge [as in the Georgia Basin in Arhan et al. (1999), and in the eastern Scotia Sea in the present work], the water mass structure is dominated by the fresher Upper WSDW of the Scotia Sea, though undercut by a thin layer of more saline Lower WSDW from around the South Sandwich Arc.

\section{Conclusions}

We have observed some significant changes in the water mass structure and circulation of the eastern Scotia Sea using two occupations of a hydrographic transect separated by just 4 years. The WDW of the WSC was observed to be warmer in 1999 than in 1995, a consequence of warmer source WDW from the Weddell Sea.

Two changes are observed in the WSDW of the eastern Scotia Sea between 1995 and 1999. First, there is a significant warming of the WSDW across the whole meridional extent of the sea at this longitude. This is accompanied by a change in salinity, whereby the potential temperature-salinity relationship in maintained, and is due to variability in the characteristics of the water overflowing the South Scotia Ridge. The second change in WSDW is a salinification of the Lower WSDW south of the southern boundary between 1995 and 1999, with no attendant change in potential temperature. This is the result of an inflow of saline Lower WSDW from the eastern side of the South Sandwich Arc via the Georgia Passage. The role of meanders of the southern boundary at Georgia Passage in permitting/ precluding this inflow is suggested, but it is also possible that the overflow of less dense WSDW at the South Scotia Ridge observed in 1999 acts to favor the inflow.

The variability in properties of WSDW overflowing the South Scotia Ridge could be caused by changes in the formation properties of the WSDW on the shelves of the Weddell Sea, as argued by Rubython et al. (2000). If this were the case, this would need to affect the density of the whole water column in the Weddell Sea beneath the depth level of the overflow and, thus, would need to be a very significant change in the thermohaline structure of the Weddell Gyre. A second possibility is that changes in the intensity of circulation of the Weddell Gyre affect the overflow properties, through changes in the depth of the isopycnals on the southern flank of the South Scotia Ridge. The intensity of the gyral circulation will depend on the integrated wind stress curl over its area. Thus we have the intriguing possibility of a change in wind forcing over a basin where deep waters form leading to changes in abyssal water properties and circulation in an adjacent basin, with the change occurring on a timescale shorter than 4 years. This therefore becomes an important process to consider for studies of the global thermohaline circulation and its role in climate variability.

Acknowledgments. We thank the officers, scientists, and crew of RRS James Clark Ross for their assistance during the fieldwork phase of this work. Two anonymous reviewers are thanked for their helpful comments. We are grateful to Alex Orsi for providing the front locations adapted in Fig. 1, and to Michel Arhan for useful advice. WOCE section A23 was funded by the Natural Environment Research Council (NERC) through Grant GST/02/575. ALBATROSS was funded by NERC through Grant GR3/11654. MPM was funded via NERC Fellowship GT5/99/MS/17.

\section{REFERENCES}

Arhan, M., K. J. Heywood, and B. A. King, 1999: The deep waters from the Southern Ocean at the entry to the Argentine Basin. Deep-Sea Res., 46, 475-499.

Bacon, S., H. M. Snaith, and M. J. Yelland, 2000: An evaluation of some recent batches of IAPSO standard seawater. J. Atmos. Oceanic Technol., 17, 854-861.

Carmack, E. C., and T. D. Foster, 1975: On the flow of water out of the Weddell Sea. Deep-Sea Res., 22, 711-724.

Coles, V. J., M. S. McCartney, D. B. Olson, and W. M. Smethie, 1996: Changes in Antarctic Bottom Water properties in the western South Atlantic in the late 1980s. J. Geophys. Res., 101 (C4), 8957-8970.

Dickson, A. G., 1994: Determination of dissolved oxygen in seawater by Winkler titration. World Ocean Circulation Experiment (WOCE) Hydrographic Program, Operations and Methods WMPO 91-1, 3-11.

Foster, T. D., and E. C. Carmack, 1976: Frontal zone mixing and Antarctic Bottom Water formation in the southern Weddell Sea. Deep-Sea Res., 23, 301-317.

Garcia, M., O. Lopez, J. Puigdefabregas, and J. Sospreda, 1997: Repeated observations of the ACC on WOCE SR1b. Int. WOCE Newslett., 29, 16-18. 
Gill, A. E., 1973: Circulation and bottom water production in the Weddell Sea. Deep-Sea Res., 20, 111-140.

Gordon, A. L., 1966: Potential temperature, oxygen and circulation of bottom water in the southern ocean. Deep-Sea Res., 13, 11251138.

Heywood, K. J., and B. A. King, 1996: WOCE section A23 cruise report. UEA Rep. Series 1, School of Environmental Sciences, University of East Anglia, Norwich, United Kingdom, 75 pp.

—_, and D. P. Stevens, 2000: ALBATROSS cruise report. UEA Rep. Series 6, School of Environmental Sciences, University of East Anglia, Norwich, United Kingdom, 61 pp.

Hogg, N. G., and W. Zenk, 1997: Long-period changes in the bottom water flowing through Vema Channel. J. Geophys. Res., 102 (C7), 15 639-15 646.

Jackett, D. R., and T. J. McDougall, 1997: A neutral density variable for the world's oceans. J. Phys. Oceanogr., 27, 237-263.

Kirkwood, D. S., 1995: Nutrients: Practical notes on their determination in seawater. ICES Techniques in Marine Environmental Sciences Rep. 17, International Council for the Exploration of the Seas, Copenhagen, Denmark, 25 pp.

Locarnini, R. A., T. Whitworth III, and W. D. Nowlin Jr., 1993: The importance of the Scotia Sea on the outflow of Weddell Sea Deep Water. J. Mar. Res., 51, 135-153.

Martinson, D. G., P. D. Killworth, and A. L. Gordon, 1982: A convective model for the Weddell Polynya. J. Phys. Oceanogr., 11, 466-488.

Meredith, M. P., K. E. Grose, E. L. McDonagh, K. J. Heywood, R. D. Frew, and P. F. Dennis, 1999: Distribution of oxygen isotopes in the water masses of Drake Passage and the South Atlantic. J. Geophys. Res., 104 (C9), 20 949-20 962.

_, R. A. Locarnini, K. A. Van Scoy, A. J. Watson, K. J. Heywood, and B. A. King, 2000: On the sources of Weddell Gyre Antarctic Bottom Water. J. Geophys. Res., 105 (C1), 1093-1104.

Orsi, A. H., W. D. Nowlin Jr., and T. Whitworth III, 1993: On the circulation and stratification of the Weddell Gyre. Deep-Sea Res., 40, 169-203.

— , T. Whitworth III, and W. D. Nowlin Jr., 1995: On the meridional extent and fronts of the Antarctic Circumpolar Current. DeepSea Res., 42, 641-673.

Peterson, R. G., and T. Whitworth III, 1989: The subantarctic and polar fronts in relation to deep water masses through the southwestern Atlantic. J. Geophys. Res., 94 (C8), 10 817-10 838.

Rubython, K. E., K. J. Heywood, and J. M. Vassie, 2001: Interannual variability of bottom temperatures in Drake Passage. J. Geophys. Res., 106 (C2), 2779-2793.

Sievers, H. A., and W. D. Nowlin Jr., 1984: The stratification and water masses at Drake Passage. J. Geophys. Res., 89 (C6), 10 489-10 514.

Smith, W. H. F., and D. T. Sandwell, 1997: Global sea floor topography from satellite altimetry and ship depth soundings. Science, 277, 1956-1962.

Thorpe, S. E., K. J. Heywood, and M. A. Brandon, 1999: Interannual variability in the Southern Ocean fronts near South Georgia and its effects on krill transport. Eos, Trans. Amer. Geophys. Union, 80, 197.

Weiss, R. F., H. G. Östlund, and H. Craig, 1979: Geochemical studies of the Weddell Sea. Deep-Sea Res., 26, 1093-1120.

Whitworth, T., III, W. D. Nowlin Jr., A. H. Orsi, R. A. Locarnini, and S. G. Smith, 1994: Weddell Sea shelf water in the Bransfield Strait and Weddell-Scotia Confluence. Deep-Sea Res., 41, 629641.

Williams, P. J. L., and N. W. Jenkinson, 1982: A transportable microprocessor-controlled precise Winkler titration suitable for field station and shipboard use. Limnol. Oceanogr., 25, 576-584. 